Daniel Engiel

Consumo de energia renovável e crescimento econômico para países em desenvolvimento

Dissertação apresentada ao Programa de Pós-Graduação em Administração de Empresas da PUC-Rio como requisito parcial para obtenção do título de Mestre em Administração de Empresas.

Orientador: Prof. Marcelo Cabus Klotzle

Rio de Janeiro

Fevereiro de 2017 
Daniel Engiel

\section{Consumo de energia renovável e crescimento econômico para países em desenvolvimento}

Dissertação apresentada como requisito parcial para obtenção do grau de Mestre pelo Programa de PósGraduação em Administração de Empresas da PUC-Rio. Aprovada pela Comissão Examinadora abaixo assinada.

Prof. Marcelo Cabus Klotzle

Orientador

Departamento de Administração - PUC-Rio

Prof. Antonio Carlos Figueiredo Pinto Departamento de Administração - PUC-Rio

Prof. André Barreira da Silva Rocha Departamento de Engenharia Industrial - PUC-Rio

Prof. Leonardo Lima Gomes Departamento de Administração - PUC-Rio

Profa. Mônica Herz

Coordenadora Setorial do Centro de Ciências Sociais - PUC-Rio

Rio de Janeiro, 06 de Fevereiro de 2017. 
Todos os direitos reservados. É proibida a reprodução total ou parcial do trabalho sem autorização da universidade, do autor e do orientador

\section{Daniel Engiel}

Graduou-se em Engenharia de Produção pela PUC-Rio, em 2010; Domínio Adicional em Empreendedorismo pela PUC-Rio, em 2010.

Ficha Catalográfica

Engiel, Daniel
Consumo de energia renovável e
crescimento econômico para países em
desenvolvimento / Daniel Engiel ; orientador:
Marcelo Cabus Klotzle. - 2017.
39 f. ; $30 \mathrm{~cm}$
Dissertação
Universidade Católica do Rio de Janeiro,
Departamento de Administração, 2017.
Inclui bibliografia
1. Administração - Teses. 2. Consumo de
energia renovável. 3. Crescimento econômico. 4.
Países em desenvolvimento. I. Klotzle, Marcelo
Cabus. II. Pontifícia Universidade Católica do Rio
de Janeiro. Departamento de Administração. III.
Título.

CDD: 658 


\section{Agradecimentos}

Agradeço ao meu orientador, professor Marcelo Klotzle, por sua paciência e generosidade, pela confiança, pela oportunidade de trabalhar ao seu lado e por ser o maior incentivador na superação de meus limites.

Agradeço às minhas avós, Deuza Martins Grinspun e Minka Engiel (in memoriam).

Agradeço aos meus avôs, Carlos Grinspun (in memoriam) e Izaak Daniel Engiel (in memoriam).

À minha mãe Sonali Grinspun Engiel.

À meu pai David Henrique Engiel.

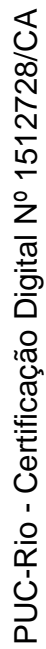

À meu irmão Bruno Engiel. 


\section{Resumo}

Engiel, Daniel; Klotzle, Marcelo Cabus. Consumo de energia renovável e crescimento econômico para países em desenvolvimento. Rio de Janeiro, 2016. 39p. Dissertação de Mestrado - Departamento de Administração, Pontifícia Universidade Católica do Rio de Janeiro.

Atualmente pode ser observado um cenário onde a expectativa é de uma enorme pressão sobre a demanda energética futura, as alarmantes consequências das emissões de dióxido de carbono na atmosfera e a realização do abastecimento energético seguro e com certo grau de previsibilidade. Assim torna-se essencial o desenvolvimento de métodos sustentáveis de geração e consumo energético. Baseado neste contexto, o presente estudo visa aprofundar o entendimento da relação entre o consumo de energia renovável e o crescimento econômico para um painel de doze países em desenvolvimento entre o os anos de 2003-2013. O teste de raiz unitária de Levin, Li e Chu bem como o modelo de dados em painel foi utilizado para inferir a relação causal entre as variáveis. O resultado revelou uma relação causal entre o PIB real, consumo de energias renováveis e formação bruta de capital fixo, como consequência dos seus respectivos coeficientes positivos e estatisticamente significativos. Entretanto, não pode ser verificado uma relação causal entre crescimento econômico e a força de trabalho.

\section{Palavras- chave}

Consumo de energia renovável; Crescimento econômico; Países em desenvolvimento. 


\section{Abstract}

Engiel, Daniel; Klotzle, Marcelo Cabus. (Advisor). Renewable energy consumption and economic growth for developing countries. Rio de Janeiro, 2016. 39p. Dissertação de Mestrado - Departamento de Administração, Pontifícia Universidade Católica do Rio de Janeiro.

Nowadays, a scenario can be observed where the expectation is that there will be enormous pressure on future energy demand, the alarming consequences of carbon dioxide emissions in the atmosphere and the realization of a secure supply of energy with a certain degree of predictability. Thus, the development of sustainable energy generation and consumption methods is essential. Based on this context, this study aims to deepen the understanding of the relationship between renewable energy consumption and economic growth for a panel of twelve developing countries between the years 2003-2013. The Levin, Li and Chu unit root test as well as the panel data model were used to infer the causal relationship between the variables. The result revealed a causal relationship between real GDP, renewable energy consumption and gross fixed capital formation, as a consequence of their respective positive and statistically significant coefficients. However, a causal relationship between economic growth and the labor force can not be verified.

\section{Keywords}

Renewable energy consumption; Economic growth; Developing countries. 


\section{Sumário}

$\begin{array}{ll}\text { 1. Introdução } & 10\end{array}$

2. Referencial Teórico 14

2.1. Fontes de Energia Renováveis $\quad 14$

2.1.1. Energia Eólica 14

2.1.2. Energia Solar $\quad 15$

2.1.3. Energia Hidrelétrica $\quad 16$

2.1.4. Energia Geotérmica 16

2.1.5. Energia da Biomassa 18

2.1.6. Energia dos Oceanos $\quad 19$

2.2. Modelos e Estudos Recentes 20

3. Metodologia $\quad 27$

3.1. Coleta de Dados e Definição de Variáveis 27

3.2. Teste Empírico 28

4. Análises e Resultados 30

5. Conclusão e Recomendações 36

6. Referências Bibliográficas $\quad 37$ 


\section{Lista de tabelas}

$\begin{array}{ll}\text { Tabela } 4.1 \text { - Estatísticas descritivas } & 30\end{array}$

Tabela 4.2 - Teste de correlação (2003-2013) 31

Tabela 4.3 - Testes de raiz unitária (2003-2013) 32

Tabela 4.4 - Modelo de dados em painel (2003-2013) 33 


\section{Lista de Acrônimos}

ARDL

DOLS

EIA

EKC

FMOLS

GEA

IEA

MENA

$$
\begin{aligned}
& \text { Auto Regressive Distributed Lags } \\
& \text { Dynamic Ordinary Least Squares }
\end{aligned}
$$

Energy Information Administration

Environmental Kuznets Curve

Panel Fully Modified OLS

Geothermal Energy Association International Energy Agency Middle East and North Africa

OCDE Organização para a Cooperação e Desenvolvimento Econômico OLS

Ordinary Least Squares

PIB

Produto Interno Bruto

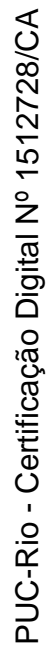

World Wind Energy Association 


\section{1. \\ Introdução}

Desde o século XIX, a energia tem desempenhado um papel fundamental no crescimento econômico e desenvolvimento da economia mundial. Entretanto, a maneira como a energia foi historicamente empregada envolveu não apenas a utilização intensa dos recursos naturais como também, muitas vezes, a sua degradação. Conforme dados do relatório Key World Statistics (IEA, 2015) aproximadamente, 66,5\% do consumo mundial de energia em 2013 foi provido da queima de combustíveis fósseis. A alta volatilidade do preço do petróleo, a dependência dos combustíveis fósseis de alguns países e os impactos ambientais causados pelas emissões de dióxido de carbono na atmosfera são algumas das principais consequências ocorridas com a obtenção de energia através de fontes de energia não renováveis.

A queda de cerca de 50\% do preço do barril de petróleo em 2015 gerou enormes mudanças geopolíticas no globo. Por ter um grande peso no comércio mundial, uma grande redistribuição de renda entre importadores e exportadores poderá ocorrer. Para os importadores representa um impulso econômico, mas para os exportadores está em jogo a viabilidade ou o colapso de seus regimes. Os primeiros aumentam pontos percentuais de PIB e diminuem o desemprego enquanto que, muitos países exportadores encaram cenários de instabilidade política econômica e enfraquecimento estratégico nas regiões mais instáveis do planeta.

A dependência de alguns países pelo abastecimento ininterrupto de petróleo ao longo dos séculos XX e XXI ocasionou inúmeros conflitos com graves consequências principalmente nas regiões produtoras de petróleo (Golfo Pérsico). Como consequência desta divisão, temos os países produtores tentando aumentar o preço dos barris e em muitos casos, diminuindo o ritmo de produção para que a demanda seja maior que a oferta (valorizando essa commodity no mercado internacional) e os países que demandam o óleo - EUA, os países da Europa Ocidental e outros emergentes como China e Índia, buscando a intervenção militar ou acordos bilaterais para manter o fornecimento ininterrupto de petróleo a preços relativamente baixos. 
No que diz respeito aos impactos ambientais ocasionados pela queima de combustíveis fósseis pode-se inferir que um dos principais é o aquecimento global. Diversos estudos apontam que a queima de combustíveis fósseis como a gasolina, o diesel e o carvão são os principais responsáveis pela emissão do $\mathrm{CO}_{2}$, ocasionando a intensificação do efeito estufa e o agravamento dos problemas vinculados ao aquecimento global.

Kaygusuz (2012) coloca que a realização do abastecimento energético seguro e com certo grau de previsibilidade e a redução da contribuição da energia para as alterações climáticas são muitas vezes referidos como os dois principais desafios enfrentados pelo setor de energia no caminho de um futuro sustentável. Além disso, atualmente bilhões de pessoas carecem dos acessos mais básicos dos serviços de energia e eletricidade aumentando assim a pressão pela utilização de energias sustentáveis.

Partindo desta contextualização do tema que será abordado, define-se o problema de pesquisa. O quanto o consumo de energia renovável pode influenciar no crescimento econômico de um determinado pais ou região geográfica?

O estudo elaborado no presente trabalho analisa a relação entre o consumo de energia renovável e o crescimento econômico (PIB) para um painel de doze países em desenvolvimento durante o período de 2003 à 2013.

Este estudo volta-se mais especificamente para abordar a questão da relação entre o consumo de energia renovável e o aumento do PIB sob o ponto de vista específico dos países em desenvolvimento. Para o desenvolvimento deste trabalho foram escolhidos, Brasil, Rússia, Índia, Colômbia, Chile, México, Indonésia, Tailândia, Vietnã, África do Sul, Turquia e Polônia. Outro fator de delimitação do estudo foi o período escolhido de 2003 até 2013 visto que a série de dados que foram encontradas para determinados países começam a ser divulgadas no ano de 2003.

Para efeitos do estudo a fonte de energia renovável hidrelétrica não foi contemplada visto que muitos países em desenvolvimento já possuem uma parcela considerável desta em sua matriz energética. Além disso, esta dissertação tem 
como objetivo avaliar o impacto das principais fontes de energia renovável que estão em crescimento acelerado para estes 12 países que serão realizados o estudo.

Cada vez mais são realizados estudos que relacionam a queima de combustíveis fósseis, principal fonte de obtenção de energia global, com o aumento da concentração dos gases de efeito estufa na atmosfera terrestre. A sociedade está descobrindo e tomando consciência dos riscos aos quais os níveis atuais de dióxido de carbono podem ocasionar no meio ambiente, como por exemplo, o aumento da temperatura média da atmosfera.

Além disso, existe a pressão pelo aumento contínuo da demanda por energia. As duas principais demandas são o crescimento orgânico da população mundial, que segundo os modelos mais atuais cresce a uma taxa exponencial, e a inclusão social daqueles que ainda estão à margem do acesso as fontes de energia. Segundo o relatório executivo World Energy Outlook (IEA, 2014) a demanda por energia irá crescer exponencialmente nos países em desenvolvimento devido a rápida expansão populacional (especialmente na África subsaariana) e a acelerada expansão econômica (especialmente na China e Índia). Com base nestas premissas, a projeção seria quase que uma duplicação do consumo atual de energia primária nas próximas duas décadas, e em sua maior parte por fontes de energia não renováveis.

Neste cenário, onde a expectativa é de uma enorme pressão sobre a demanda energética futura, torna-se iminente o investimento em fontes de energia renováveis. Conforme Sadorsky (2009), dada a importância que o consumo de energia renovável vai desempenhar nas próximas décadas, é surpreendente que tão pouco trabalho tenha sido realizado sobre a relação entre o consumo de energia renovável e renda e isso é especialmente verdadeiro no caso das economias emergentes já que estas são aquelas que irão experimentar o maior aumento na demanda de energia e como consequência a emissões de dióxido de carbono.

O presente trabalho visa aprofundar o entendimento da relação entre o crescimento do PIB e o aumento do consumo de energias renováveis em países em desenvolvimento. Além disso, o material realizado poderá servir de base para discussões sobre o desenvolvimento e modernização do setor energético e ser 
utilizado como argumento para fins que levem a um futuro mais sustentável. Dado que o assunto ainda é pouco explorado, o estudo também se propõe a ser fonte de desenvolvimentos posteriores.

Esta dissertação está dividida em seis capítulos. Este primeiro capítulo contextualiza o presente estudo, delimita seus objetivos e discorre sobre sua relevância e escopo. O segundo capítulo faz uma revisão das principais fontes renováveis de energia e uma breve revisão da literatura que aborda os temas de energia renovável e crescimento econômico. O terceiro capítulo explicita a proposição da pesquisa, a escolha das variáveis utilizadas para a construção do modelo proposto, discorre sobre o método de pesquisa utilizado e sobre a forma como foram feitas as coletas de dados. O quarto capítulo é sobre as análises realizadas sobre os dados coletados e os resultados obtidos enquanto o quinto capítulo traz as conclusões e recomendações para futuros estudos. O sexto e último capítulo traz as referências bibliográficas. 


\section{2. \\ Referencial teórico}

Neste capítulo discute-se de forma resumida a função das fontes renováveis de energia, os principais desafios para o seu desenvolvimento e qual será o seu papel no longo prazo. Em seguida, é levantada a literatura referente aos modelos e estudos já traçados a fim de criar um ambiente favorável para o seu posterior desenvolvimento.

\section{1. Fontes de Energia Renováveis}

As fontes de energia renováveis, como o próprio nome explicita, são aquelas que possuem a capacidade de serem repostas naturalmente, o que não significa que todas elas sejam inesgotáveis. Algumas delas, como o vento e a luz solar são permanentes, mas outras como a água podem acabar, e isso irá depender da forma como o ser humano irá utilizá-la. É importante ressaltar que nem toda fonte renovável de energia é limpa, ou seja, está livre da emissão de poluentes ou de impactos ambientais em larga escala.

De acordo com a Agência de Informação de Energia (IEA), as fontes de energia renováveis são naturalmente reabastecidas em um período relativamente curto de tempo. As principais fontes de energia renovável incluem a biomassa, a geotérmica, a hídrica, a solar, a dos ventos e a dos oceanos (ondas e marés); nos parágrafos seguintes irão ser abordadas cada uma destas fontes de energia.

\subsection{1.}

\section{Energia Eólica}

A energia eólica tem como principal recurso o vento. Eles ativam turbinas e geradores dos chamados aerogeradores que convertem esta energia mecânica em energia elétrica. Esta energia ainda não é tão difundida em razão do alto custo de seus equipamentos e pelo seu perfil de geração que é dependente de um recurso 
natural que tem um padrão de disponibilidade incerto, tornando-se essa a principal dificuldade de comercializar esta energia.

Entretanto, alguns países desenvolvidos já vêm adotando esse recurso, com destaque para os Estados Unidos, China e Alemanha. Suas principais vantagens são a não emissão de dióxido de carbono e poluição na atmosfera e mitigar as incertezas quanto à oferta internacional de petróleo e gás.

Segundo a World Wind Energy Association (WWEA, 2015), a capacidade instalada eólica a nível mundial atingiu 393 gigawatts (GW) em junho desse ano. O parque mundial instalado de centrais eólicas já pode gerar cerca de $4 \%$ da demanda de eletricidade mundial. Um crescimento de 5,8\% nos últimos seis meses e 16,8\% em comparação com o acumulado até 2014.

\subsection{2. \\ Energia Solar}

A energia solar ocorre pelo aproveitamento da luz do sol para a geração de eletricidade e também para o aquecimento da água. Existem duas formas de aproveitamento da energia solar: a fotovoltaica e a térmica. No primeiro caso, são utilizadas células específicas que lançam o chamado "efeito fotoelétrico" para a produção de eletricidade. No segundo caso, utiliza-se o aquecimento da água tanto para uso direto quanto para a geração de vapor, que atuará em processos de ativação de geradores de energia.

Devido aos elevados custos, principalmente dos painéis fotovoltaicos, a energia solar ainda não é muito utilizada. Porém, com o aumento gradual do consumo, seu custo unitário vem diminuindo ao longo dos anos devido aos ganhos de escala desta indústria. Segundo a Solar Power Europe, declínios de preço do sistema fotovoltaico de cerca de $75 \%$ em menos de 10 anos têm trazido energia solar perto de competitividade de custos em diversos países e segmentos de mercado.

Segundo a Solar Power Europe, em 2014 foram adicionados pelo menos 40 gigawatts $(\mathrm{GW})$ de painéis fotovoltaicos com a sua instalação em todo o 
mundo no ano de 2014, acima dos 37 gigawatts (GW) em 2013 estabelecendo um novo recorde para o setor de energia solar fotovoltaica. O setor global de energia solar fotovoltaica experimentou um novo ano de crescimento em 2014 atingindo uma capacidade instalada acumulada de 178 gigawatts (GW).

\subsection{3.}

\section{Energia Hidrelétrica}

A energia hidrelétrica é obtida pelo aproveitamento da água dos rios para a movimentação das turbinas de eletricidade. Nas usinas hidroelétricas, constroemse barragens no leito do rio para o represamento da água que será utilizada no processo de geração de eletricidade. Nesse caso, o mais aconselhável é a construção de barragens em rios que apresentem desníveis em seus terrenos, com o objetivo de diminuir a superfície inundada. Por isso, é mais recomendável a instalação dessas usinas em rios de planalto, embora também seja possível em rios de planícies, porém com impactos ambientais maiores.

Para efeitos do estudo a fonte de energia renovável hidrelétrica não foi contemplada visto que muitos países em desenvolvimento já possuem uma parcela considerável desta em sua matriz energética. Além disso, esta dissertação tem como objetivo avaliar o impacto das principais fontes de energia renovável que estão em crescimento acelerado no contexto dos 12 países que serão utilizados como amostra do estudo.

\subsection{4.}

\section{Energia Geotérmica}

A energia geotérmica se caracteriza pelo calor proveniente da superfície da crosta terrestre. A energia elétrica pode ser obtida através da perfuração do solo em locais onde há grande quantidade de vapor, estes devem ser drenados até a superfície terrestre por meio de tubulações específicas. Em seguida o vapor é transportado a uma central elétrica geotérmica, que irá girar as lâminas de uma 
turbina. Por fim, a energia obtida através da movimentação das lâminas (energia mecânica) é transformada em energia elétrica através do gerador.

O principal benefício desta fonte de energia é que praticamente não há emissão de gases poluentes (dióxido de carbono e dióxido de enxofre), não intensificando o chamado efeito de estufa. Os maiores obstáculos para o seu desenvolvimento são o alto custo da obtenção da energia, pois necessita de altos investimentos estruturais e sua baixa eficiência, além de, caso seja usada de forma desenfreada pode ocasionar o esgotamento do campo geotérmico.

Segundo o relatório GEA International, (GEA, 2010) a energia geotérmica tem ajudado muito países em desenvolvimento como o Quênia, Indonésia e muitas ilhas do Caribe. Este modelo de energia pode dar respostas a necessidades de infraestrutura, preservando o meio ambiente dessas regiões. Muitos países em desenvolvimento estão buscando a independência energética e econômica ao mesmo tempo que aprendem com as lições, tanto positivas como negativas, das práticas comerciais e de subsídios empregados pelos países desenvolvidos. Austrália, China, Alemanha, Islândia, Itália, Japão e os EUA são alguns dos países mais desenvolvidos que estão facilitando projetos que ampliem a matriz geotérmica em todo o mundo. Este apoio inclui financiamento, bem como a partilha de tecnologia, treinamento e pesquisas geológicas.

O Sistema Rift Africano é outra das maiores reservas geotérmicas conhecidas do mundo, e as necessidades de energia no continente africano são um tema de interesse internacional. A produção de biomassa tem levado ao desmatamento indesejado, e as secas tem diminuído o volume de água dos rios afetando a oferta de energia hidroelétrica. Recursos geotérmicos do Sistema Rift poderiam fornecer uma fonte própria de geração de energia com uma fonte previsível e um preço mais acessível para os locais mais remotos da África. 


\subsection{5. \\ Energia da Biomassa}

A energia provida da biomassa consiste na queima de substâncias de origem orgânica para a produção de energia, ocorrendo por meio da combustão de materiais como a lenha, o bagaço de cana e outros resíduos agrícolas, restos florestais e até excrementos de animais. É considerada uma fonte de energia renovável porque o dióxido de carbono produzido durante a queima é utilizado pela própria vegetação na realização da fotossíntese, o que significa que, desde que haja controle, o seu uso é sustentável por não alterar a macro composição da atmosfera terrestre.

Os biocombustíveis, são considerados um exemplo de biomassa, pois são produzidos a partir de vegetais de origem orgânica para a geração de combustível que é empregado principalmente nos meios de transporte. O exemplo mais conhecido é o etanol produzido da cana-de-açúcar, mas podem existir outros compostos advindos de vegetais como a mamona, o milho, entre outros.

Segundo a Agência Internacional de Energia (IEA, 2014), a bioenergia tradicional e moderna representa cerca de $10 \%$ da oferta total de energia primária mundial hoje. A maior parte desta é consumida nos países em desenvolvimento para cozinhar e aquecer, usando fogueiras muito ineficientes ou simples fogões com impacto considerável na saúde (poluição causada pela fumaça) e meio ambiente (desmatamento). Em 2013, a geração de energia moderna de biomassa atingiu um valor estimado de 396 TWh, acima dos 379 TWh produzidos em 2012 (crescimento de 4,3\%). Os Estados Unidos continuam sendo o maior produtor (64 TWh em 2013), seguido da Alemanha, onde foram gerados 48 gigawatts (GW) de bioenergia.

Em circunstâncias favoráveis, a produção de energia a partir de biomassa pode ter um custo competitivo. No entanto, em muitos casos, os incentivos econômicos são necessários para cobrir as diferenças de custo entre a bioenergia e a energia produzida através dos combustíveis fósseis. As medidas de apoio devem ser sustentadas por uma legislação que equilibre a necessidade de energia com outros objetivos, tais como a redução de gases que geram o efeito estufa, a segurança alimentar, a biodiversidade e o desenvolvimento sócio econômico. 


\subsection{6. \\ Energia dos Oceanos}

Atualmente existem diferentes tecnologias para a obtenção da energia dos oceanos, são elas, a energia das marés, energia das ondas, gradiente térmico e salinidade. Porém, as tecnologias mais representativas atualmente são a energia das marés e a energia das ondas, estas deverão ser as primeiras a se tornarem viáveis comercialmente. Os próximos parágrafos irão evidenciar como se dá o processo de transformação de energia de cada uma dessas fontes energéticas assim como suas vantagens, desvantagens e seus principais desafios para a aceleração do seu desenvolvimento.

A energia das marés é obtida por meio do aproveitamento da energia proveniente do desnível das marés. Para que essa energia seja revertida em eletricidade é necessária a construção de barragens, eclusas (permitindo a entrada e saída de água) e unidades geradoras de energia. As barragens são construídas próximas ao mar, e os diques são responsáveis pela captação de água durante a alta da maré, então a água é armazenada e, em seguida, é liberada durante a baixa da maré, passando por uma turbina que gera energia elétrica.

As vantagens desta fonte de energia são a constância e previsibilidade da ocorrência das marés, o fato das marés serem uma fonte inesgotável de energia e serem uma fonte de energia não poluente ao meio ambiente. A principal desvantagem deste modelo de energia é, essencialmente, o custo do investimento. Dado que a instalação de uma usina que utilize a maré como fonte de energia ter um custo muito elevado e visto que seus custos operacionais também são consideravelmente altos (além da rápida depreciação que ocorre em função da água do mar) este modelo de geração de energia ainda tem muito a ser desenvolvido até tornar-se economicamente e comercialmente viável.

A energia das ondas baseia-se no movimento da água que resulta da força do vento e transporta energia cinética que pode ser aproveitada por dispositivos próprios para a captação dessa energia. Atualmente existe uma grande variedade de tecnologias e sistemas para o aproveitamento da energia das ondas e podemos classificá-las dependendo do local de instalação. Em resumo, existem três diferentes tecnologias de captação de energia das ondas: Shoreline, sistema 
instalado na costa, o Near-shore, sistema instalado perto da costa (cerca de 20 metros de profundidade) e o Offshore, sistema de captação em águas mais profundas (cerca de 30 a 60 metros de profundidade). Este tipo de aproveitamento pode ser considerado recente e ainda em fase de desenvolvimento.

\section{2. \\ Modelos e Estudos Recentes}

Em uma série de estudos recentes, a relação causal entre o consumo de energia renovável e crescimento econômico tem sido investigada. Em um estudo de medidas de consumo de energia desagregados para a Turquia durante o período de 1969-1999, Sari e Soytas (2004) encontraram em termos de fontes de energia renováveis que o consumo de resíduos explica 17,3\% da variação do PIB real; o consumo de energia hidroelétrica explica 10,6\%; e o consumo de biomassa explica cerca de $3,5 \%$.

Usando a mesma abordagem que Sari e Soytas (2004), mas para os EUA durante o período mensal de dados entre os anos de 2001 a 2005, Ewing et al. (2007) constataram que para um período de 25 meses a energia hidrelétrica explicou cerca de 1,9\% da variação da produção industrial; a energia solar explicou cerca de 3,8\%; a energia provinda de resíduos explicou 10,6\%; a energia da biomassa cerca de 6\%; a energia eólica cerca de 5,8\%; e o consumo total de energia renovável cerca de $2,4 \%$.

Sari et al. (2008) estimaram um modelo ARDL usando dados mensais entre os anos de 2001 e 2005 sobre os EUA. Seus resultados indicaram que a produção industrial tem um impacto positivo e o emprego um impacto negativo, respectivamente, em hidrelétrica, resíduos e consumo de energia eólica. Por outro lado, a produção industrial tem um impacto negativo e o emprego um impacto positivo sobre o consumo de energia solar, enquanto que nem a produção industrial nem o emprego tem um impacto estatisticamente significativo sobre o consumo de energia da biomassa. 
Dentro de um modelo de dados em painel para dezoito economias emergentes ao longo do período 1994-2003, Sadorsky (2009b) apresentou uma evidência de causalidade bidirecional entre o consumo de energia renovável e de crescimento econômico. Concentrando a atenção sobre os EUA para o período 1949-2006, Payne (2009a) empregou o procedimento Toda-Yamamoto para testar a causalidade de Granger dentro de uma metodologia de dados em painel, com a inclusão de capital e trabalho para encontrar a ausência de uma relação causal entre o consumo de energia renovável e o crescimento econômico. Em uma análise da relação causal entre o consumo de energias renováveis por setor do PIB real nos EUA para o período 1949-2006, Bowden e Payne (2009) revelaram a causalidade unidirecional do consumo de energias renováveis residencial e produção real, enquanto a ausência de uma relação causal em relação ao consumo comercial e industrial de energia renovável e crescimento econômico real, respectivamente.

Apergis e Payne (2009), apresentaram um estudo que analisa a relação entre o consumo de energia renovável e de crescimento econômico para um painel de vinte países da OCDE entre o período 1985-2005. Como o período dos dados de séries temporais pode ser considerado curto, um modelo de cointegração em painel e correção de erro foi utilizado para inferir a relação causal. O resultado revelou uma relação de equilíbrio de longo prazo entre o PIB real, consumo de energias renováveis, formação bruta de capital fixo real, e de força de trabalho como consequência dos respectivos coeficientes positivos e estatisticamente significativos.

Em 2010, Apergis e Payne novamente realizaram um estudo que analisou a relação entre o consumo de energia renovável e de crescimento econômico com a diferença de agora ser para um painel de seis países da América Central no período 1980-2006. O resultado do estudo revelou uma relação de equilíbrio de longo prazo entre o PIB real, consumo de energias renováveis, a formação bruta de capital fixo real, e da força de trabalho com os respectivos coeficientes positivos e estatisticamente significativos. Os resultados do modelo de correção de erro do painel indicaram uma causalidade bidirecional entre o consumo de energia renovável e do crescimento econômico de curto e longo prazo. 
Menyah e Wolde-Rufael (2010), analisaram a relação causal entre as emissões de dióxido de carbono $\left(\mathrm{CO}_{2}\right)$, consumo de energia renovável, energia nuclear e PIB real para os EUA entre o período de 1960 à 2007. Utilizando uma versão modificada do teste de causalidade de Granger, encontraram uma causalidade unidirecional entre o consumo de energia nuclear e as emissões de $\mathrm{CO}_{2}$. Entretanto, não foi identificada uma causalidade de energia renovável e emissões de $\mathrm{CO}_{2}$. As evidências econométricas pareceram sugerir que o consumo de energia nuclear pode contribuir para mitigar as emissões de $\mathrm{CO}_{2}$, mas até agora, o consumo de energia renovável não atingiu um nível em que pode fazer uma contribuição significativa para a redução de emissões.

Fei, Li et al. (2011) investigaram a relação entre consumo de energia e crescimento econômico para 30 províncias da China continental de 1985 a 2007. Os resultados empíricos mostraram que há uma relação positiva de longo prazo entre o PIB real per capita e as variáveis de consumo de energia. Além disso, investigaram dois grupos inter-regionais, distribuídos da seguinte forma, China Oriental e China Ocidental, e obtiveram resultados e implicações mais relevantes que os anteriores. No longo prazo, um aumento de $1 \%$ do PIB real per capita aumenta o consumo de energia em aproximadamente entre 0,48\% e 0,50\% e, consequentemente, aumenta a emissão de dióxido de carbono em cerca de $0,41 \%$ a $0,43 \%$ na China. O crescimento econômico no leste da China é, em sua maioria, energético dependente, e a elasticidade-renda do consumo de energia da China Oriental é mais de duas vezes o da China Ocidental. Atualmente, a China está sujeita a enormes pressões para mitigar as mudanças climáticas.

Arouri, Mohammed EI Heidi et al. (2012) estenderam as recentes descobertas de Liu (2005), Ang (2007), Apergis et al. (2009) e Payne (2010), através da implementação de testes recentes de raiz unitária e técnicas de cointegração para investigar a relação entre as emissões de dióxido de carbono, o consumo de energia e o PIB real de 12 países do Oriente Médio e do Norte da África (MENA) entre o período de 1981-2005. Os resultados mostraram que, no longo prazo, o consumo de energia tem um impacto positivo significativo nas emissões de $\mathrm{CO}_{2}$. Além disso, foi evidenciado que o PIB real exibe uma relação quadrática com as emissões de $\mathrm{CO}_{2}$ para a região como um todo. No entanto, 
embora os coeficientes estimados de rendimento a longo prazo e o seu quadrado satisfaçam a hipótese de EKC na maioria dos países estudados, os pontos de inflexão são muito baixos em alguns casos e muito elevados noutros casos, fornecendo assim evidências precárias em apoio da hipótese EKC. Assim, os resultados sugerem que nem todos os países da região MENA precisam sacrificar o crescimento econômico para diminuir seus níveis de emissão, pois podem alcançar a redução das emissões de $\mathrm{CO}_{2}$ via conservação de energia sem efeitos negativos a longo prazo sobre o crescimento econômico. De acordo com a hipótese da Curva Ambiental de Kuznets (EKC), à medida que a renda aumenta, as emissões também aumentam até que algum nível do limiar da renda seja atingido após o qual as emissões começam a diminuir.

Pao HT e Fu HC (2013), empregaram as estatísticas anuais do Brasil de 1980 a 2010 para explorar as relações causais entre o PIB real e quatro tipos de consumo de energia: consumo de energia renovável não-hidrelétrica (NHREC), consumo total de energia renovável (TREC), consumo de energia não renovável (NREC) e o consumo total de energia primária (TEC). O teste de cointegração revelou um equilíbrio de longo prazo entre o PIB real, o trabalho, o capital e cada um dos quatro tipos de consumo. O desenvolvimento da economia brasileira está extremamente ligado à formação de capital e à força de trabalho. A influência de NHREC e TREC na produção real é positiva e significativa, enquanto que os impactos por NREC e TEC são insignificantes. Os resultados dos modelos de correção de erros vetoriais revelaram uma causalidade unidirecional da NHREC para o crescimento econômico, uma causalidade bidirecional entre crescimento econômico e TREC e uma causalidade unidirecional do crescimento econômico para NREC ou TEC sem retorno no longo prazo. Esses achados sugerem que o Brasil é uma economia independente de energia e que o crescimento econômico é crucial para prover os recursos necessários para o desenvolvimento sustentável. A expansão das energias renováveis não só aumentaria o crescimento econômico do Brasil e conteria a deterioração do meio ambiente, mas também criaria uma oportunidade para um papel de liderança no sistema internacional e melhoraria a concorrência do Brasil com os países mais desenvolvidos. 
Ohler e Fetters (2014), analisaram a relação causal entre o crescimento econômico e a geração de eletricidade a partir de fontes renováveis de energia (biomassa, geotérmica, hidrelétrica, solar, resíduos e eólica) em 20 países da OCDE no período de 1990 a 2008. Os resultados baseados em um modelo de dados em painel encontrados foram (i) uma relação bidirecional entre a geração renovável de energia agregada e PIB real, (ii) as energias provindas da biomassa, da hidroeletricidade, dos resíduos e a energia eólica exibem uma relação de longo prazo positiva com o PIB, (iii) a hidroeletricidade e a geração de resíduos apresentam uma relação bidirecional positiva de curto prazo com o crescimento do PIB, e (iv) a biomassa, a hidroeletricidade e a geração de eletricidade através dos resíduos têm o maior impacto sobre o PIB real no longo prazo.

Ucan, Aricioglu e Yucel (2014), analisaram a relação entre o consumo de energia renovável, energia não-renovável e crescimento econômico para um painel de quinze países da União Europeia durante o período 1990-2011. Os testes de cointegração heterogêneos apresentaram uma relação de equilíbrio de longo prazo entre o PIB real, consumo de energia renovável e não renovável, emissões de gases de efeito estufa e pesquisa e desenvolvimento. Os resultados de causalidade de Granger demonstraram uma causalidade unidirecional entre o consumo de energia não renovável e o crescimento econômico.

Usama Al-mulali e Abdul Hakim Mohammed (2015), objetivaram investigar a relação entre o produto interno bruto (PIB) por setor econômico e consumo de energia por tipo para 16 países emergentes entre os anos de 1980 e 2010. A metodologia foi baseada em um modelo de dados em painel com estes 16 países ao longo de um período pré-determinado. Os resultados obtidos revelaram que o PIB por setor da economia e consumo por tipo de energia são cointegrados. Além disso, a causalidade de Granger concluiu uma relação causal bidirecional entre o petróleo, gás natural e consumo de energias renováveis e os setores de manufatura, industrial e de serviços. Este estudo recomenda que esses países devem aumentar seu consumo de energia renovável para alcançar o seu crescimento do PIB.

Tang, Tan e Oxturk (2015), analisaram a relação entre o consumo de energia e o crescimento econômico no Vietnã entre o período 1971-2011. Os 
métodos de cointegração e causalidade de Granger foram utilizados para estabelecer a relação entre as variáveis de interesse. Os resultados confirmaram a existência de cointegração entre as variáveis. Em particular, o consumo de energia, o investimento externo direto (IED) e o capital social foram estatisticamente significantes em influenciar positivamente o crescimento econômico no Vietnã. O teste de causalidade de Granger revelou causalidade unidirecional do consumo de energia para o crescimento econômico. Por isso, o Vietnã é uma economia dependente de energia e qualquer política energética ou ambiental elaborada para tentar reduzir a expansão energética desse país irá comprometer o processo de desenvolvimento econômico do Vietnã. Por esta razão, deveria ser dada atenção a política de energia renovável para fornecer suprimentos suficientes para acelerar a expansão econômica.

Bhattacharya, Mita et al. (2016), investigaram os efeitos do consumo de energia renovável sobre o crescimento econômico dos principais países consumidores de energia renováveis no mundo. Usando o Índice de Energia Renovável País Atratividade desenvolvido pela Ernst \& Young Global Limited, foram escolhidos os 38 principais países em termos de consumo de energia renovável para explicar o processo de crescimento entre 1991 e 2012. Foi confirmada a relação de longo prazo entre o crescimento econômico e de energia renovável. Achados de elasticidades-produto de longo prazo indicam que o consumo de energias renováveis tem um impacto positivo significativo sobre a produção econômica de $57 \%$ dos países selecionados. Para a robustez, foram também realizadas análises de séries temporais de elasticidades-produto de longo prazo. Os resultados sugeriram que os governos, planejadores de energia, agências de cooperação internacionais e órgãos envolvidos deveriam agir em conjunto, aumentando o investimento em energia renovável para o crescimento econômico na maioria desses países.

Ali, Hamusi Sadi et al. (2016), examinaram as relações entre o consumo de energia da biomassa, o capital social, o capital humano e o crescimento econômico para países da África Subsaariana selecionados com base no modelo de dados em painel. A descoberta revelou que o consumo de energia de biomassa, capital social e capital humano são estatisticamente significativos, o que significa 
que as variáveis acima mencionadas têm um impacto positivo e significativo sobre o crescimento econômico para os países estudados. Quando técnicas de estimativa de cointegração em painel, OLS dinâmicas (DOLS) e OLS totalmente modificados (FMOLS) foram aplicadas, o resultado revela que o consumo de energia de biomassa, capital social, capital humano e crescimento econômico são cointegradas com a hipótese nula da maioria das estatísticas rejeitada ao nível de $1 \%$ de significância. A conclusão baseada no FMOLS mostra que o consumo de energia de biomassa, capital social e capital humano influencia positivamente o crescimento econômico ao nível de $1 \%$ e o mesmo resultado é obtido a partir do painel de OLS. O resultado com base em DOLS no entanto, revela que o consumo de energia de biomassa e do capital social são significativos a $1 \%$ no crescimento econômico, enquanto o capital humano não é significante. Considerando o seu efeito positivo sobre o crescimento econômico com pouca degradação ambiental em comparação com os usos de combustíveis fósseis, o consumo de energia de biomassa é mais preferível nesses países. 


\section{3. \\ Metodologia}

\section{1.}

\section{Coleta de Dados e Definição de Variáveis}

A pesquisa realizada foi uma pesquisa de caráter quantitativo com coleta de uma amostra de dados que visam relacionar crescimento econômico e consumo de energia renovável de doze países em desenvolvimento num período determinado de tempo.

Os dados anuais de 2003 a 2013, foram obtidos a partir dos Indicadores de Desenvolvimento do Banco Mundial e da Agência de Informação de Energia para os seguintes países, Brasil, Rússia, Índia, Colômbia, Chile, México, Indonésia, Tailândia, Vietnã, África do Sul, Turquia e Polônia. Para o critério de seleção desses países foi considerada uma amostra de países espalhadas pelo mundo, isto para não enviesar a análise e resultado de uma região geográfica específica.

O modelo de dados em painel inclui o PIB Real (Y) em dólares constantes de 2005 nos EUA, formação bruta de capital fixo (K) em dólares constantes de 2005 nos EUA, e da força de trabalho (L) em milhões. No que diz respeito ao consumo de energia renovável (RE), neste estudo é definido em milhões de quilowatts-hora e constitui-se das energias geotérmica, solar, eólica, biomassa e consumo de energia elétrica de resíduos.

Seguindo os estudos de Bowden e Payne (2009), Payne (2009a) e Apergis e Payne (2009) a relação causal entre o consumo de energia renováveis e o crescimento econômico foi realizado dentro de modelo de dados em painel com a inclusão de medidas de capital (K) e trabalho (L) para abordar a questão do viés de variável omitida. Todas as variáveis estão em logaritmos naturais.

O estudo estará delimitado a observação de doze países em desenvolvimento no período entre os anos de 2003 a 2013. Com base nesse universo, coletou-se uma amostra de dados que visam relacionar crescimento econômico e consumo de energia renovável utilizando as variáveis, PIB, formação 
bruta de capital fixo, força de trabalho e participação de fontes renováveis de energia com exceção da energia hidroelétrica.

A presente pesquisa pode ser considerada aplicada, com relação a sua natureza, uma vez que objetiva entender e auxiliar no processo de relacionar crescimento econômico e consumo de energia renovável. Afim de que países em desenvolvimento possam utilizá-la como forma de fomentar o crescimento da participação de energia renovável em suas respectivas economias.

\section{2. \\ Teste Empírico}

Primeiramente, o teste de raiz unitária de Levin, Li e Chu (2002) foi utilizado o que permite verificar se os coeficientes auto-regressivos são heterogêneos. Isso significa dizer que as variáveis temporais são estacionárias. Uma série temporal é dita estacionária quando ela se desenvolve no tempo aleatoriamente ao redor de uma média constante, refletindo alguma forma de equilíbrio estável. Na prática, a maioria das séries que encontramos apresentam algum tipo de não estacionariedade como, por exemplo, tendência. Segue abaixo a descrição da fórmula do teste de raiz unitária de Levin, Li e Chu (2002);

$$
y_{i t}=\rho_{i} y_{i t-1}+\delta_{i} X_{i t}+\varepsilon_{i t}
$$

onde $\mathrm{i}=1, \ldots, \mathrm{N}$ para cada país no painel; $\mathrm{t}=1, \ldots, \mathrm{T}$ refere-se ao período de tempo; $Y_{\text {it }}$ representa o PIB real em dólares constantes de 2005 nos EUA; $X_{\text {it }}$ representa variáveis exógenas no modelo incluindo efeitos fixos ou tendência temporal individual; $\rho_{\mathrm{i}}$ os coeficientes auto regressivos; e o $\varepsilon_{\text {it }}$ os termos dos erros estacionários. Foi utilizado o teste de Levin, Li e Chu (2002) para a realização dos testes de raiz unitária, já que o mesmo apresenta um maior poder para modelos com dados em painel.

O modelo de Levin, Li e Chu (2002) é uma extensão do teste de raiz unitária de Dickey-Fuller (DF). Os autores argumentam que testes de raiz unitária individuais possuem poder limitado contra hipóteses alternativas com desvios 
altamente persistentes do equilíbrio, o que ocorre mais frequentemente em pequenas amostras. Assim, Levin, Li e Chu (2002) sugerem um teste de raiz unitária mais poderoso em relação à aplicação de testes individuais a cada seção transversal.

A hipótese nula refere-se a um processo comum de raiz unitária onde a hipótese nula é de que a série tenha raiz unitária, e portanto não seja estacionária, abaixo

$$
\begin{aligned}
& \text { H0 : tem raiz unitária (não é estacionária) } \\
& \text { H1 : não tem raiz unitária (é estacionária) }
\end{aligned}
$$

Após os resultados dos testes de raiz unitária, foi utilzado o modelo de dados em painel de mínimos quadrados já corrigo por White no Cross-Section para uma maior robustez do modelo como se segue:

$$
Y_{i t}=\alpha_{i}+\delta_{i t}+\gamma_{1 i} R E_{i t}+\gamma_{2 i} K_{i t}+\gamma_{3 i} L_{i t}+\varepsilon_{i t}
$$

onde $\mathrm{i}=1, \ldots, \mathrm{N}$ para cada país no painel $\mathrm{t}=1, \ldots, \mathrm{T}$ refere-se ao período de tempo. Os parâmetros $\alpha_{\mathrm{i}} \mathrm{e} \delta_{\mathrm{it}}$ permitem a possibilidade de efeitos fixos específicos de cada país e as tendências determinísticas, respectivamente. $\varepsilon_{\text {it }}$ denotam os resíduos estimados que representam desvios do relacionamento de longo prazo.

A variável Y representa o PIB real em dólares constantes de 2005 nos EUA; a variável RE representa o consumo de energia renovável em milhões de quilowatts-hora e constitui-se das energias geotérmica, solar, eólica, biomassa e consumo de energia elétrica de resíduos; a variável K representa a formação bruta de capital fixo em dólares constantes de 2005 nos EUA; e a variável L representa a força de trabalho em milhões. 


\section{4.}

\section{Análises e Resultados}

Nesta seção são apresentados os resultados encontrados nas análises estatísticas e econométricas dos dados, e que juntamente com a teoria de base proposta anteriormente pode-se avaliar os objetivos propostos para este estudo.

Primeiramente, mais abaixo na Tabela 4.1, serão apresentadas as estatísticas descritivas (média, mediana, máximo, mínimo, desvio-padrão, assimetria e curtose) com as variáveis utilizadas no modelo econométrico de dados em painel.

Tabela 4.1 - Estatísticas descritivas

\begin{tabular}{lcccc}
\hline & ENERGIA & DTRABALHO & DCAPITAL & DPIB \\
\hline Média & 0.212 & 1.593 & 1.156 & 4.537 \\
Mediana & 0.218 & 1.596 & 2.215 & 4.982 \\
Máximo & 0.724 & 6.036 & 26.772 & 9.767 \\
Mínimo & 0.003 & -1.776 & -37.718 & -8.143 \\
Desvio Padrão & 0.165 & 1.385 & 10.164 & 2.800 \\
Assimetria & 0.749 & 0.335 & -0.853 & -1.425 \\
Curtose & 3.121 & 3.602 & 5.295 & 7.002 \\
\hline & & & & \\
Observações & 120 & 120 & 120 & 120 \\
\hline
\end{tabular}

Antes de analisar a Tabela 4.1 acima torna-se necessária a definição das variáveis ENERGIA, DTRABALHO, DCAPITAL e DPIB. A variável ENERGIA é definida como a variável energia renovável em valor absoluto; a variável DTRABALHO é definida como sendo a primeira diferença da variável trabalho; a variável DCAPITAL é definida como sendo a primeira diferença da variável formação bruta de capital fixo real e a variável DPIB é a primeira diferença da variável PIB real. 
A partir da Tabela 4.1 acima descrita, pode ser evidenciado que para os países em desenvolvimento selecionados no estudo $21 \%$ de sua matriz energética está relacionada com o consumo de fontes de energia renovável (excluindo a energia hidrelétrica) com um desvio-padrão relativamente baixo de 16,5\%, dentro do período de tempo analisado.

Outro fator interessante de ser mencionado a partir dos dados da Tabela 4.1 está na variável da primeira diferença do PIB. Pode-se notar que a variação do crescimento econômico para estes países teve uma média relativamente alta, 4,5\% no período analisado. Ademais, ressalta-se o crescimento econômico da Índia de +9,7\% comparando-se a ano de 2010 contra 2009 como sendo o valor máximo da variação do PIB na amostra apurada. O valor mínimo da variação do PIB de $8,14 \%$ demonstra a retração da economia da Rússia quando comparado o ano de 2009 com o ano de 2008.

Fica evidente que os crescimentos e quedas mencionados acima tem uma relevância importante se for considerado o período analisado pelo estudo, entre os anos de 2003 a 2013. Neste período, ocorreu a crise do subprime, afetando a economia mundial como um todo, que teve seu auge no ano de 2008 com a falência do banco Lehman Brothers. A economia mundial em 2009 teve seu pior desempenho, registrando queda de 2,07\% do PIB em comparação com o ano de 2008.

No que tange a variação do trabalho, pode ser dito que seu valor máximo de $+6,04 \%$ ocorreu no Chile quando comparado os anos de 2010 e 2009 e o seu valor mínimo de $-1,78 \%$, ou seja, um aumento do desemprego ocorrido na África do Sul entre os anos de 2004 e 2003. Já sobre a variação de capital teve seu menor valor, de $-34,73 \%$, na Turquia quando comparados os anos de 2009 e 2008. O valor negativo apresentado na Turquia pode ser interpretado como um desinvestimento em capital no período acima citado.

Pode-se observar também que os parâmetros utilizados para estimar o modelo estão em primeira diferença com exceção da variável Energia. Isto devese ao fato de que a variável energia em nível já ser estacionária, mais a frente 
iremos realizar os testes de raiz unitária para confirmar que as demais variáveis são estacionárias na primeira diferença.

No intuito de testar a existência de multicolinearidade no modelo proposto foi realizado um teste de correlação entre todas as variáveis da regressão.

Tabela 4.2 - Teste de correlação (2003-2013)

\begin{tabular}{lccc}
\hline Variáveis & ENERGIA & DTRABALHO & DCAPITAL \\
\hline ENERGIA & 1.000 & 0.213 & 0.017 \\
DTRABALHO & 0.213 & 1.000 & 0.077 \\
DCAPITAL & 0.017 & 0.077 & 1.000 \\
\hline
\end{tabular}

Como demonstrado na tabela 4.2, pode-se observar que todas as variáveis apresentam os coeficientes de correlação menor ou muito próxima de $20 \%$. Isto significa dizer que não existe uma correlação significativa e, portanto, não podemos afirmar que exista multicolinearidade no modelo proposto.

A análise de regressão baseada em séries temporais ou dados em painel como utilizado neste estudo, supõe implicitamente que essas séries sejam estacionárias, ou seja, estão sendo geradas por um processo estocástico ou aleatório.

Os testes de raiz unitária têm como principal finalidade verificar a ordem de integração das séries econômicas, ou seja, o número de diferenças necessárias para que a série se torne estacionária. Constatado que uma série é gerada por um processo estacionário, isto implica que os choques serão transitórios e deverão se dissipar num horizonte curto de tempo. A seguir seguem os resultados encontrados para cada uma das variáveis que compõe o modelo. 
Tabela 4.3 - Testes de raiz unitária (2003-2013)

\begin{tabular}{lccc}
\hline \hline \multicolumn{4}{c}{ Levin, Li e Chu (LLC) } \\
\hline Variáveis & Estatística & Valor $p$ & Observações \\
\hline & & & \\
\hline DPIB & -578.237 & 0.0000 & 96 \\
DCAPITAL & -471.947 & 0.0000 & 96 \\
DTRABALHO & -801.260 & 0.0000 & 96 \\
ENERGIA & -136.024 & 0.0869 & 108 \\
\hline \hline
\end{tabular}

O resultado da Tabela 4.3 aponta que a primeira diferença das variáveis DPIB, DCAPITAL e DTRABALHO não possuem raízes unitárias, ou seja, são estacionárias na primeira diferença e todas significantes no nível de $1 \%$. Além disso, pode ser observado que a variável ENERGIA em nível é estacionária com 10\% de significância. Portanto, todas as variáveis do modelo assim determinadas não possuem raízes unitárias e portanto são estacionárias.

Após o teste de raízes unitárias, foi rodado o modelo de dados em painel que pode ser visto conforme Tabela 4.4 abaixo.

Tabela 4.4 - Modelo de dados em painel (2003-2013)

\begin{tabular}{lcccc}
\hline Variáveis Independentes & Coeficiente & Desvio Padrão & Estatística-T & Significância \\
\hline \hline C & 3,8912 & 0,5427 & 7,1689 & 0,0000 \\
ENERGIA & 2,9871 & 0,8726 & 3,4230 & 0,0009 \\
DCAPITAL & 0,1679 & 0,0456 & 3,6768 & 0,0004 \\
DTRABALHO & $-0,1143$ & 0,1317 & $-0,8684$ & 0,3869 \\
\hline \hline R-Quadrado & 0,3997 & Média var. dep. & 4,5376 \\
R-Quadrado Ajustado & 0,3841 & D. Padrão var. dep. & 2,8007 \\
Erro padrão regressão & 2,1978 & Critério de Akaike & 4,4455 \\
Soma quadr. resíduos & 560,33 & Critério de Schwarz & 4,5385 \\
Log Verossimilhança & $-262,73$ & Critério de Hannan-Quinn & 4,4833 \\
Estatística F & 25,746 & Durbin-Watson & 1,3465 \\
Prob(F) & 0,0000 & & \\
\hline \hline
\end{tabular}

O modelo de dados em painel foi estimado de maneira robusta já sendo corrigido por White no cross-section, sem efeitos aleatórios ou efeitos fixos. Os coeficientes das variáveis energia e a primeira diferença da formação bruta de capital fixo são positivos e estatisticamente significativos ao nível de significância 
de $1 \%$. Entretanto, o coeficiente da primeira diferença da variável trabalho é negativo e não significante.

Podemos atribuir a não significância da primeira diferença da variável trabalho observando o perfil de países escolhidos e o período no qual o modelo foi estimado. Os doze países escolhidos possuem característica de serem capitais intensivos, da relação de países selecionados todos, com exceção da Polônia, possuem um percentual da formação bruta de capital fixo sobre o PIB real maior do que $20 \%$ no ano de 2013. Alguns países, como a Indonésia e a Índia, possuem percentuais acima de 30\%, considerado alto quando comparados aos demais países do mundo.

Dado que as variáveis são expressas em logaritmos naturais, os coeficientes podem ser interpretados como estimativas de elasticidade. Os resultados indicam que um aumento de $1 \%$ no consumo de energia renovável aumenta o PIB real em 2,98\%; um aumento de $1 \%$ na formação bruta real de capital fixo aumenta o PIB real em $0,16 \%$.

Estes resultados vão de encontro a diversos trabalhos já realizados ao longo dos últimos anos. O estudo apresentado por Apergis e Payne (2009) para os países da OCDE, evidenciou uma relação positiva e significante ao nível de $1 \%$ entre o PIB real e todas as variáveis independentes do modelo, consumo de energia renovável, formação bruta de capital fixo e trabalho, todas em primeira diferença.

Os resultados do estudo realizado por Sadorsky (2009) apresentou que as estimativas de cointegração dos painéis mostraram que aumentos da renda real per capita têm um impacto positivo e estatisticamente significativo no consumo per capita de energia renovável. A longo prazo, um aumento de $1 \%$ na renda real per capita aumenta o consumo de energia renovável per capita nas economias emergentes em cerca de $3,5 \%$.

No estudo de Apergis e Payne (2010), foi comprovada também a relação entre crescimento econômico e o consumo de energia renovável com a diferença de agora ser para um painel de seis países da América Central. O resultado do 
estudo revelou uma relação de equilíbrio entre o PIB real, consumo de energia renovável, formação bruta de capital fixo, e força de trabalho com os respectivos coeficientes positivos e estatisticamente significativos. 


\section{5. \\ Conclusão e Recomendações}

Esse trabalho pretendeu investigar a relação causal entre o crescimento econômico e o consumo de energia renovável utilizando o modelo de dados de painel para doze países em desenvolvimento durante o período 2003-2013. Os resultados das estimativas do painel revelaram que há uma relação causal com significância ao nível de 1\%, entre o PIB real, o consumo de energia renovável e a formação bruta de capital fixo. Entretanto, não pode ser verificado uma relação causal entre crescimento econômico e a força de trabalho.

Essa relação indicou que um aumento de $1 \%$ no consumo de energia renovável aumenta o PIB real em 2,98\%, um aumento de $1 \%$ na formação bruta real de capital fixo aumenta o PIB real em $0,16 \%$. Uma das hipóteses para a força de trabalho não ter sido significante no modelo tem como causa as características dos países selecionados. A grande maioria da amostra dos países selecionados são capitais intensivos, ou seja, o percentual do PIB real referente a formação bruta de capital fixo é alto, ocasionando assim a perda de poder explicativo da variável força de trabalho no modelo.

Este resultado reitera a importância das energias renováveis para o crescimento econômico sustentável. Com o desenvolvimento e expansão das fontes de energias renováveis poderá ocorrer a redução da dependência de fontes de energia estrangeiras, a volatilidade do preço do petróleo e do gás natural e reduzirá a degradação ambiental de médio e longo prazo associada às emissões de gases que causam o efeito estufa.

Como sugestão para estudos futuros, a adição de novas variáveis ao modelo e o aumento da quantidade amostral. Esse aumento da amostra pode se dar acrescendo a quantidade de países ou estendendo o período de tempo do estudo de forma com que o mesmo torne-se mais verossímil. 


\section{6. Referências Bibliográficas}

ALI, Hamisu Sadi et al. Dynamic implication of biomass energy consumption on economic growth in Sub-Saharan Africa: evidence from panel data analysis. GeoJournal, p. 1-10.

APERGIS, Nicholas; PAYNE, James E. CO 2 emissions, energy usage, and output in Central America. Energy Policy, v. 37, n. 8, p. 3282-3286, 2009.

APERGIS, Nicholas; PAYNE, James E. Energy consumption and economic growth in Central America: evidence from a panel cointegration and error correction model. Energy Economics, v. 31, n. 2, p. 211-216, 2009.

APERGIS, Nicholas; PAYNE, James E. Energy consumption and economic growth: evidence from the Commonwealth of Independent States. Energy Economics, v. 31, n. 5, p. 641-647, 2009.

APERGIS, Nicholas; PAYNE, James E. The emissions, energy consumption, and growth nexus: evidence from the commonwealth of independent states. Energy Policy, v. 38, n. 1, p. 650-655, 2010.

AROURI, Mohamed El Hedi et al. Energy consumption, economic growth and CO 2 emissions in Middle East and North African countries. Energy Policy, v. 45, p. 342-349, 2012.

BHATTACHARYA, Mita et al. The effect of renewable energy consumption on economic growth: Evidence from top 38 countries. Applied Energy, v. 162, p. 733-741, 2016.

Empresa de Pesquisa Energética (EPE); Balanço Energético Nacional 2015 (BEN 2015), Ministério das Minas e Energia; www.mme.gov.br, acessada em Janeiro 2016.

EWING, Bradley T.; SARI, Ramazan; SOYTAS, Ugur. Disaggregate energy consumption and industrial output in the United States. Energy Policy, v. 35, n. 2, p. 1274-1281, 2007.

FEI, Li et al. Energy consumption-economic growth relationship and carbon dioxide emissions in China. Energy policy, v. 39, n. 2, p. 568-574, 2011.

FREIRE, Lucas. Modelo de Comercialização de Energia Renovável no Ambiente de Contratação Livre via Teoria de Jogos Cooperativos. 2013. Tese de Doutorado. PUC-Rio.

Geothermal Energy Association (GEA); www.geo-energy.org, acessada em Janeiro 2016. 
International Energy Agency (IEA); Key World Energy Statistics 2015.

International Energy Agency (IEA); Renewable Energy Medium-Term Market Report 2014.

International Energy Agency (IEA); World Energy Outlook 2014.

International Energy Agency (IEA); www.iea.org, acessada em Janeiro 2016.

KAYGUSUZ, K.; YÜKSEK, Ö.; SARI, A. Renewable energy sources in the European Union: Markets and capacity. Energy Sources, Part B: Economics, Planning, and Policy, v. 2, n. 1, p. 19-29, 2007.

KAYGUSUZ, Kamil. Energy for sustainable development: A case of developing countries. Renewable and Sustainable Energy Reviews, v. 16, n. 2, p. 11161126, 2012.

KAYGUSUZ, Kamil. Energy for sustainable development: key issues and challenges. Energy Sources, Part B: Economics, Planning, and Policy, v. 2, n. 1, p. 73-83, 2007.

MENYAH, Kojo; WOLDE-RUFAEL, Yemane. CO 2 emissions, nuclear energy, renewable energy and economic growth in the US. Energy Policy, v. 38, n. 6, p. 2911-2915, 2010.

PAO, Hsiao-Tien; FU, Hsin-Chia. Renewable energy, non-renewable energy and economic growth in Brazil. Renewable and Sustainable Energy Reviews, v. 25, p. 381-392, 2013.

PAYNE, James E. A survey of the electricity consumption-growth literature. Applied energy, v. 87, n. 3, p. 723-731, 2010.

PAYNE, James E. On the dynamics of energy consumption and output in the US. Applied Energy, v. 86, n. 4, p. 575-577, 2009.

PAYNE, James E. Survey of the international evidence on the causal relationship between energy consumption and growth. Journal of Economic Studies, v. 37, n. 1, p. 53-95, 2010.

PEDRONI, Peter et al. Critical values for cointegration tests in heterogeneous panels with multiple regressors. Oxford Bulletin of Economics and statistics, v. 61, n. s 1, p. 653-670, 1999.

PEDRONI, Peter. FULLY MODIFIED OLS FOR HETEROGENEOUS COINTEGRATED PANELS. 2000.

PEDRONI, Peter. Panel cointegration: asymptotic and finite sample properties of pooled time series tests with an application to the PPP hypothesis. Econometric theory, v. 20, n. 03, p. 597-625, 2004. 
SADORSKY, Perry. Renewable energy consumption and income in emerging economies. Energy policy, v. 37, n. 10, p. 4021-4028, 2009.

SADORSKY, Perry. Renewable energy consumption and income in emerging economies. Energy policy, v. 37, n. 10, p. 4021-4028, 2009.

SADORSKY, Perry. Renewable energy consumption, CO 2 emissions and oil prices in the G7 countries. Energy Economics, v. 31, n. 3, p. 456-462, 2009.

SARI, Ramazan; EWING, Bradley T.; SOYTAS, Ugur. The relationship between disaggregate energy consumption and industrial production in the United States: an ARDL approach. Energy Economics, v. 30, n. 5, p. 2302-2313, 2008.

SARI, Ramazan; SOYTAS, Ugur. Disaggregate energy consumption, employment and income in Turkey. Energy Economics, v. 26, n. 3, p. 335-344, 2004.

TANG, Chor Foon; TAN, Bee Wah; OZTURK, Ilhan. Energy consumption and economic growth in Vietnam. Renewable and Sustainable Energy Reviews, v. 54, p. 1506-1514, 2016.

UCAN, Okyay; ARICIOGLU, Ebru; YUCEL, Fatih. Energy consumption and economic growth nexus: evidence from developed countries in Europe. International Journal of Energy Economics and Policy, v. 4, n. 3, p. 411, 2014.

World Wind Energy Association (WWEA); www.wwindea.org, acessada em Janeiro 2016. 